\title{
Prediction of Container Haulage Demand using GM(1,1) Model
}

\author{
Fengyun $\mathrm{He}^{1, a}$, Pengjun Zheng ${ }^{2, b^{*}}$ and Zhengfeng Huang ${ }^{3, \mathrm{c}}$ \\ 1,2,3 Ningbo University Faculty of Maritime and Transportation, China, Zhejiang Province, Ningbo, \\ 315211 \\ a1032567689@qq.com, bzhengpengjun@nbu.edu.cn, chuangzhengfeng@nbu.edu.cn \\ *The corresponding author
}

Keywords: Container Haulage; Demand; Supply-Demand Balance Method; GM(1,1) Model

\begin{abstract}
The reasonable estimation of container haulage demand is significant for the container transportation in port cities. Based on the number of container trucks and container throughput from year 2009 to 2015 in Ning bo Port, container haulage demand is predicted using $\operatorname{GM}(1,1)$ model, the result is compared to prediction using supply-demand balance method, it is shown that the $\operatorname{GM}(1,1)$ model has better prediction accuracy and fitting than supply-demand balance method.
\end{abstract}

\section{Introduction}

The correct estimation of haulage demand has a great significance for the container transportation industry. The demand characteristics of container haulage are directly affected by the container turnover of the port and mode split between haulage and other modes such as train, river transport etc. Supply- demand balance method is suitable for predicting future demands for haulage industries.

Supply- demand balance method usually considers many related factors and has been applied in forecasting the quantity of urban taxi [1]. However, it is usually difficult to obtain accurate data for mode split which is required for supply-demand balance methods. $\operatorname{GM}(1,1)$ is the typical grey forecasting model in grey theory systems which was founded by Deng Julong [2], and it may be superior to perform in the condition of small sample and poor information [3]. Vallée [4] introduced the development of grey system theory systematically and concluded that GM $(1,1)$ was suitable for limited data. Ene and Öztürk [5] optimized the parameters in $\operatorname{GM}(1,1)$ model using Fourier series and Markov chain correction with a small amount of the most recent data. Which method will be better in forecasting for container truck is the question what we research.

\section{Overview of GM(1,1) Model}

GM $(1,1)$ model is composed of a first-order differential equation of one single variable. It is mainly used in a complex system with fitting and forecasting characteristics to reveal changes in the dominant factors and the future development trend of change [6]. It has been widely used to carry out quantitative forecasts and reasonable prediction accuracy was obtained [7] [8]. In this paper, a GM(1,1) model was developed to predict the demand for container trucks in a port.

The actual demand of container trucks from year 2009 to 2015 in Ningbo is taken as the raw data $\mathrm{X}^{(0)}$,then predicts the $\mathrm{X}^{(0)}$.

$$
\begin{aligned}
& \text { Assume } \mathrm{X}^{(0)}=\left(x^{(0)}(1), x^{(0)}(2), \ldots \ldots, x^{(0)}(n)\right) \text { and } x^{(0)}(k) \geqslant 0(k=1,2, \ldots \ldots, \mathrm{n}) . \\
& \mathrm{X}^{(1)} \text { is accumated by } \mathrm{X}^{(0)}, \text { and } x^{(1)}(k)=\sum_{i=1}^{k} x^{(0)}(i)(k=1,2, \ldots \ldots, n) . \\
& \mathrm{X}^{(1)}=\left(x^{(1)}(1) x^{(1)}(2) x^{(1)}(3), \ldots \ldots, x^{(1)}(n)\right) \\
& \mathrm{Z}^{(1)} \text { is the generated mean sequence defined as } \\
& \mathrm{Z}^{(1)}=\left(z^{(1)}(2), z^{(1)}(3), \ldots \ldots, z^{(1)}(n)\right)
\end{aligned}
$$

Where

$$
{ }_{z}^{(1)}(k)=0.5 \times\left(x^{(1)}(k)+x^{(1)}(k-1)\right)(\mathrm{k}=1,2, \ldots \ldots, n)
$$


The differential equation of GM (1,1) model is as follows:

$$
\frac{d x^{(1)}}{d t}+a x^{(1)}(t)=b
$$

The weighted model parameters of GM $(1,1)$ is determined by least square method for $x^{(1)}$.

$$
a=\left[\begin{array}{ll}
a & b
\end{array}\right]^{\mathrm{T}}=\left(\mathrm{B}^{\mathrm{T}} \mathrm{B}\right)^{-1} \mathrm{~B}^{\mathrm{T}} \mathrm{Y}
$$

Where:

$$
\mathrm{Y}=\left[\begin{array}{c}
x^{(0)}(2) \\
x^{(0)}(3) \\
\vdots \\
x^{(0)}(n)
\end{array}\right] \quad \mathrm{B}=\left[\begin{array}{cc}
-{ }^{(1)}(2) & 1 \\
-z^{(1)}(3) & 1 \\
\vdots & \vdots \\
-{ }^{(1)}(n) & 1
\end{array}\right]
$$

Solution of $\mathrm{X}^{(1)}$ is below:

$$
x^{(1)}(k+1)=\left(x^{(0)}(1)-\frac{b}{a}\right) \mathrm{e}^{-a k}+\frac{\mathbf{b}}{\mathbf{a}}
$$

$\mathrm{GM}(1,1)$ model is established as follows:

$$
x^{(0)}(k+1)=x^{(1)}(k+1)-x^{(1)}(k)
$$

According to Chen [9] et al., we can get that the prediction accuracy of GM $(1,1)$ model that can be determined by the relative error, absolute correlation degree, mean square error and small probability error of the model, and these four indicators are also applicable to supply-demand balance method $[10]$.

\section{Overview of Supply-Demand Balance Method}

Supply-demand balance method has a certain forecasting function, most researchers [11-13] apply this method to taxi capacity configuration and all get a reasonable prediction. According to the actual demand of the container throughput, using this method to get the total amount demand of trucks.

Let $\mathrm{W}$ be total amount of transporting container by truck:

$\mathrm{W}=\mathrm{T} \times \mathrm{F} \times \mathrm{D} \times \mathrm{P}$

where, $T$ is the container throughput, $F$ is the daily average times of truck transportation, $D$ is the average truck transportation distance, and $P$ is the proportion of the containers using truck transportation.

Let $\mathrm{K}$ be total transportation distance:

$\mathrm{K}=\frac{\mathrm{W}}{\mathrm{H}}$

where $H$ refers to the quantity of containers transported in one day ( 24 hours).

In the transporting process may appear the empty driving phenomenon, we should consider this factor, using $E$ to represent:

$$
E=1-\frac{K}{t \times V \times N}
$$

where $N$ is total amount of container trucks, $t$ is the average transportation time of truck, $V$ is the average transportation speed of truck.

The quantity of container truck $N$ can be obtained using.

$$
\mathrm{N}=\frac{\mathrm{K}}{(1-\mathrm{E}) \times \mathrm{t} \times \mathrm{V}}
$$

\section{Prediction of Haulage Demand for Ningbo}

We use Ningbo as an example to demonstrate the application of above methods for the prediction of haulage demand. In order to accurately forecast the quantity of Ningbo truck, the supply- demand 
balance method and GM $(1,1$,$) are applied respectively for comparison. Relevant data on the haulage$ statistics, container throughput, proportion of the truck transportation and the number of truck are obtained from Ningbo Municipal Bureau of Statistics [14], which is shown in Table 1 and Table 2.

Table 1 The volume of container haulage from 2009-2015

\begin{tabular}{|c|c|c|c|}
\hline Year & Truck quantity & $\begin{array}{l}\text { Container throughput } \\
/ 10^{4} \text { teu }\end{array}$ & Proportion of the truck transportation \\
\hline 2009 & 7500 & 1042.30 & $83.33 \%$ \\
\hline 2010 & 9694 & 1300.35 & $83.98 \%$ \\
\hline 2011 & 11036 & 1451.24 & $83.18 \%$ \\
\hline 2012 & 11791 & 1567.14 & $79.52 \%$ \\
\hline 2013 & 11557 & 1677.40 & $71.72 \%$ \\
\hline 2014 & 14710 & 1870.00 & $69.98 \%$ \\
\hline 2015 & 15850 & 1982.70 & $66.43 \%$ \\
\hline
\end{tabular}

Table 2 Haulage Statistics

\begin{tabular}{ccccc}
\hline $\begin{array}{c}\text { Daily average } \\
\text { jouneys per truck }\end{array}$ & $\begin{array}{c}\text { Average } \\
\text { jouney } \\
\text { distance } \\
/ \mathrm{km}\end{array}$ & $\begin{array}{c}\text { Daily average } \\
\text { shipment volume per } \\
\text { truck } \\
\text { /teu }\end{array}$ & $\begin{array}{c}\text { Daily average } \\
\text { journey time per } \\
\text { truck } / \text { hour }\end{array}$ & $\begin{array}{c}\text { Average speed } \\
\text { of truck } / \mathrm{kpm}\end{array}$ \\
\hline 8 & 48.344 & 16 & 14 & 67.50 \\
\hline
\end{tabular}

\section{Results}

The predicted haulage demand in terms of number of trucks for container transportation is calculated using supply-demand balance method and $\operatorname{GM}(1,1)$ model respectively. Accuracy of prediction is analyzed using relative error, absolute correlation degree, mean square error and small probability error; these are showed in Table 3.

Table 3 Results and error analysis

\begin{tabular}{|c|c|c|c|c|c|c|c|}
\hline \multirow[b]{2}{*}{ Year } & \multirow[b]{2}{*}{ Actual } & \multicolumn{3}{|c|}{ Supply-demand balance method } & \multicolumn{3}{|c|}{ GM $(1,1)$ model } \\
\hline & & $\begin{array}{l}\text { Model } \\
\text { prediction }\end{array}$ & Residual & $\begin{array}{l}\text { Relative } \\
\text { error }\end{array}$ & $\begin{array}{l}\text { Model } \\
\text { prediction }\end{array}$ & Residual & $\begin{array}{l}\text { Relative } \\
\text { error }\end{array}$ \\
\hline 2009 & 7550 & 8038.1364 & -488.1464 & -0.0065 & 7550.0000 & 0.0000 & 0.0000 \\
\hline 2010 & 9694 & 9301.4906 & 392.5094 & 0.0405 & 9596.8171 & 97.1829 & 0.0100 \\
\hline 2011 & 11036 & 10569.0298 & 466.9702 & 0.0423 & 10580.4489 & 455.5511 & 0.0413 \\
\hline 2012 & 11791 & 11825.6808 & -34.6808 & -0.0029 & 11664.8986 & 126.1014 & 0.0107 \\
\hline 2013 & 11557 & 13056.3692 & -1499.3692 & -0.1297 & 12860.4997 & -1303.4997 & -0.1128 \\
\hline 2014 & 14710 & 14246.0389 & 463.9611 & 0.0315 & 14178.6446 & 531.3554 & 0.0361 \\
\hline 2015 & 15850 & 15379.6157 & 470.3843 & 0.0297 & 15631.8937 & 218.1063 & 0.0138 \\
\hline \multicolumn{3}{|c|}{ Average Relative error } & \multicolumn{2}{|c|}{0.0488} & \multicolumn{3}{|l|}{0.0321} \\
\hline \multicolumn{3}{|c|}{ Absolute correlation degree } & \multicolumn{2}{|c|}{0.9061} & \multicolumn{3}{|l|}{0.9176} \\
\hline \multicolumn{3}{|c|}{ Mean square error } & \multicolumn{2}{|c|}{0.0058} & \multicolumn{3}{|l|}{0.0471} \\
\hline \multicolumn{3}{|c|}{ Small probability error } & \multicolumn{2}{|c|}{1} & \multicolumn{3}{|l|}{1} \\
\hline \multicolumn{3}{|c|}{ Accuracy class } & \multicolumn{2}{|c|}{ II } & \multicolumn{3}{|l|}{ II } \\
\hline
\end{tabular}


(1) The result of supply-demand balance method. Relative error $=0.0488$, absolute correlation degree $=0.9061$, mean square error $=0.0042$, small error probability $=1$, accuracy class is II.

(2) The result of GM $(1,1)$ model. Relative error $=0.0321$, absolute correlation degree $=0.9,176$, mean square error $=0.0471$, small error probability $=1$, accuracy class is II.

The residual data of the supply-demand balance method and the GM $(1,1)$ model are shown in Fig.1. It can be seen that the GM $(1,1)$ model is more accurate with smaller residual data.

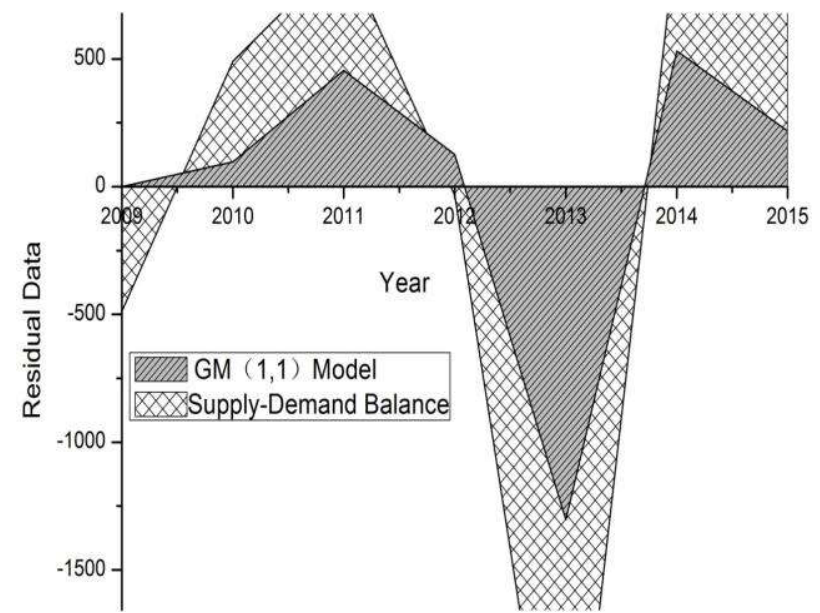

Figure 1. Residual data comparison

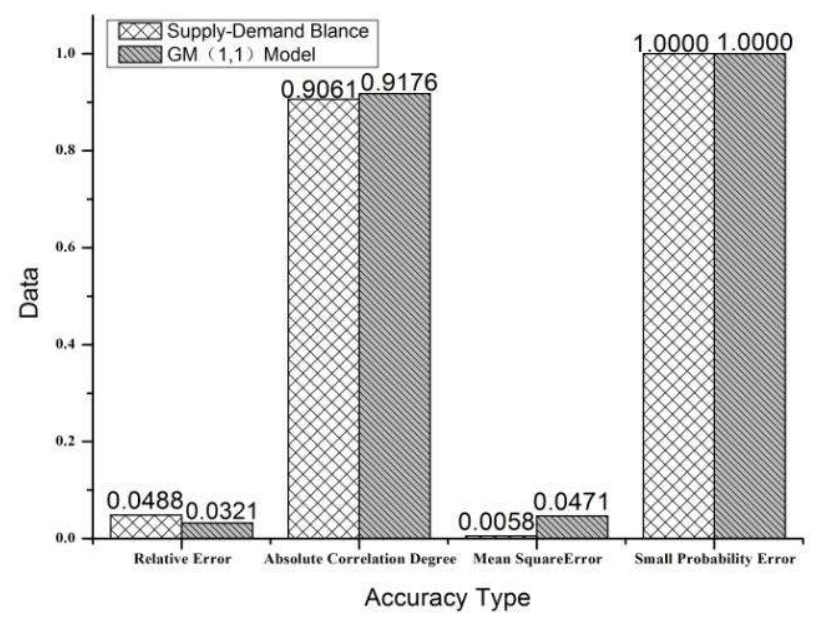

Figure 2. Four accuracy indexes comparison

Comparison of four prediction error indicators is shown in Fig. 2. It can be observed that GM $(1,1)$ model has better performance in relative error and absolute correlation degree, but in terms of mean square error and square error ratio, supply and demand balance method is better. Overall, the GM $(1,1)$ mode is more accurate.

The fitting curve of supply-demand balance method and GM $(1,1)$ model with the actual data is shown in Fig.3.

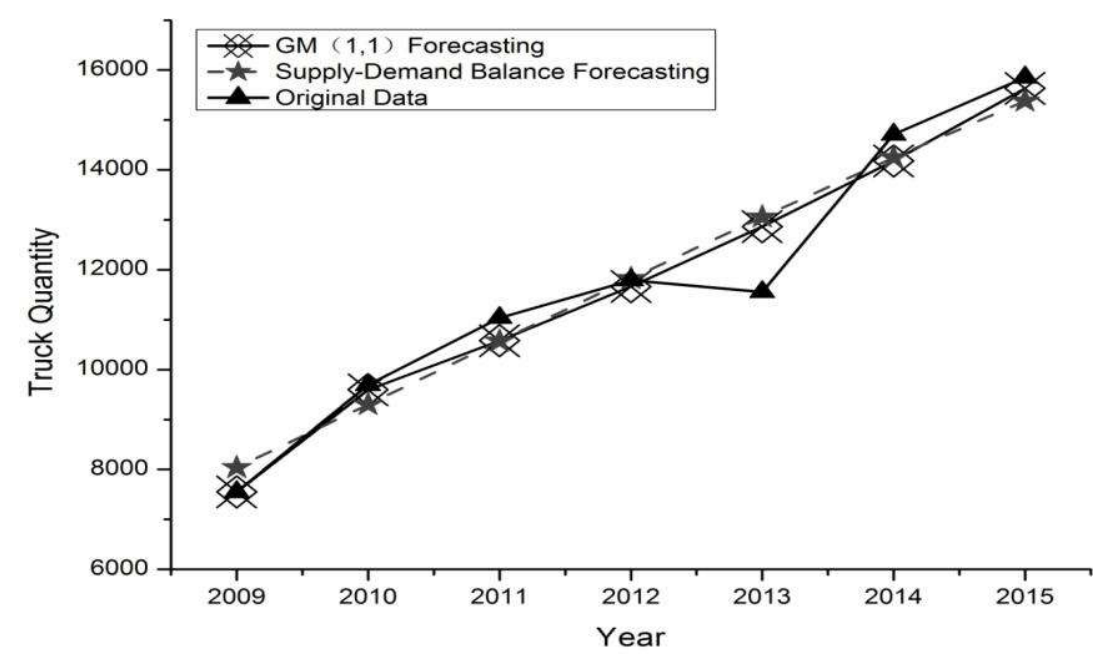

Figure 3. Fitting between model prediction and actual data

It can be seen that the supply-demand balance method and GM $(1,1)$ model all have a good fit with actual data, with the GM $(1,1)$ model having a slightly higher degree of fit .

\section{Conclusions}

Based on the comparison of demand-supply balance method and GM $(1,1)$ model performance in predicting haulage demand of Ningbo between 2009 and 2015, it can be concluded that: 
(1) Through the comparison of residual data, prediction error indicators and degree of fitting, the GM $(1,1)$ model is slightly better than demand-supply balance method. It is therefore suggested that GM $(1,1)$ model may be used to predict haulage demands.

(2) Using fitted GM $(1,1)$ model, it can be predicted that the haulage demand in terms of number of container trucks in 2016 and 2017 will be 17,234 and 19,000 respectively, which means that the relevant government department should manage the truck quantity to avoid over supply of haulage capacity.

\section{Acknowledgements}

This paper is supported in part by National Natural Science Foundation of China (Grant No. 51408321), Zhejiang Provincial Natural Science Foundation of China (Grant No. LY15E080013) and EC Project Civitas-Portis (690713).

\section{References}

[1] J. Zhou, Z.T. Zhu: Hierarchy Analysis and Strategies on the Imbalance Between Supply and Demand of Urban Traffic, Journal of Transportation Systems Engineering and Information Technology, Vol.7(2007), No.4, p.24.

[2] W. Zhou, J.M. He: Generalized GM(1,1) Model and Its Application in Forecasting of Fuel Production, Applied mathematical Modeling, Vol.37(2013), No.9, p.6234.

[3] C.I. Chen, S.J. Huang: The Necessary and Sufficient Condition for GM(1,1) Grey Prediction Model, Applied Mathematics and Computation, Vol.219(2013),No.11, p.6152.

[4] R. Vallée: Grey Information: Theory and Practical Applications, Kybernetes, Vol.37(2008), No.1, p.89.

[5] S. Ene, N. Öztürk: Grey Modeling Based Forecasting System for Return Flow of End-of-life Vehicles, Technological Forecasting and Social Change, Vol.115 (2017) No.3, p.155.

[6] J.L. Deng : Foundation of Grey Theory (Huazhong University of Science and Technology Press, China 2002), p.2. (In Chinese)

[7] R. Rajesh: Forecasting Supply Chain Resilience Performance Using Grey Prediction, Electronic Commerce Research and Applications, Vol.20 (2016) No.20, p.42.

[8] Anton Bezuglov, Gurcan Comert: Short-term freeway traffic parameter prediction: Application of grey system theory models, Expert Systems with Applications, Vol.62 (2016) No.62, p.284.

[9] C.Y. Chen, R. Dai and T.T. Yang: Study on container throughput prediction of shanghai port based on improved GM(1,1) model, Ship \& Ocean Engineering, Vol. 45 (2016) No.4, p.153. (In Chinese)

[10] S.F. Liu, Y.G. Dang and Z.G. Fang: Grey System Theory and Application (Science Press, China 2010), p.146. (In Chinese)

[11]X.G Hu: Research on the Reasonable Capacity of Taxi in Dalian (MS., Dalian Polytechnic University, China 2013), p.7. (In Chinese)

[12]Z.J. Liu: Research on the Reasonable Development Scale of the Taxi in Jinan City (MS., Tianjin University, China 2013), p.29. (In Chinese)

[13]D.L. Zhang, Y.H. Kang and W. Liu: Research on the resource allocation of taxi, Journal of Technology Innovation and Application, Vol.5 (2016) No.4, p.3. (In Chinese)

[14] Information on http://www.nbstats.gov.cn/tjnj/2004njbg.htm 